\title{
THE PRESENCE OF CONGENITAL HYPERTROPHY OF THE RETINAL PIGMENT EPITHELIUM IN A SUBGROUP OF PATIENTS WITH ADENOMATOUS POLYPOSIS COLI MUTATIONS
}

\author{
A. C. RECK ${ }^{1}$, D. BUNYAN ${ }^{2}$, D. ECCLES ${ }^{3}$ and R. HUMPHRY ${ }^{1}$ \\ Salisbury and Southampton
}

\begin{abstract}
SUMMARY
Patients expressing congenital hypertrophy of the retinal pigment epithelium (CHRPE) are clustered within specific families with familial adenomatous polyposis (FAP). CHRPE has been found to be dependent on the position of the mutation in the adenomatous polyposis coli (APC) gene. The significance of the CHRPE finding in view of this new evidence is discussed.
\end{abstract}

Familial adenomatous polyposis (FAP) is a precancerous disease whose hallmark is the development of multiple colorectal adenomas each of which has the inherent risk to become a carcinoma. In some patients extra-intestinal manifestations are found including epidermoid cysts, osteomas, desmoid tumours (Gardner's syndrome) and congenital hypertrophy of the retinal pigment epithelium (CHRPE).

The adenomatous polyposis coli (APC) gene responsible for FAP has been cloned and more than 250 different mutations have been identified. The correlation between the location of the mutation in the APC gene and the clinical picture has been investigated, and the CHRPE status of an individual is now known to be closely associated with the position of the mutation site. Patients with mutations between codons 312 and 1444 are CHRPE-positive, whilst mutations in other sites result in a CHRPEnegative phenotype. ${ }^{1,2}$

Patients with characterised mutations within the APC gene were examined for the presence or absence of CHRPE. They were divided into two

From: ${ }^{1}$ Department of Ophthalmology and ${ }^{2}$ Wessex Clinical Genetics Laboratory, Salisbury District Hospital; ${ }^{3}$ Wessex Clinical Genetics Unit, Princess Anne Hospital, Southampton UK.

Correspondence to: Miss A. C. Reck, Eye Unit, Southampton District Hospital, Tremona Road, Southampton SO16 6YD, UK. groups: group 1, individuals with mutations prior to exon 9 in the APC gene; group 2, individuals with mutations distal to exon 9 in the gene. CHRPE lesions are characteristically well demarcated, pigmented, flat and either round or ovoid (Fig. 1). Occasionally, a hypopigmented halo may be seen around the lesions and depigmented areas within the lesion may be present (Fig. 2) ${ }^{1,3}$ The Iesions occur bilaterally but there is often considerable difference in CHRPE expressivity in the two fundi. CHRPE enlargement may occur slowly over time. ${ }^{1}$ Histopathological studies have shown an increase in concentration of pigment granules in enlarged retinal pigment epithelial cells and degeneration of the overlying photoreceptors. ${ }^{4}$

This study was designed to examine a group of known FAP patients in order to confirm the correlation of mutation site with CHRPE status.

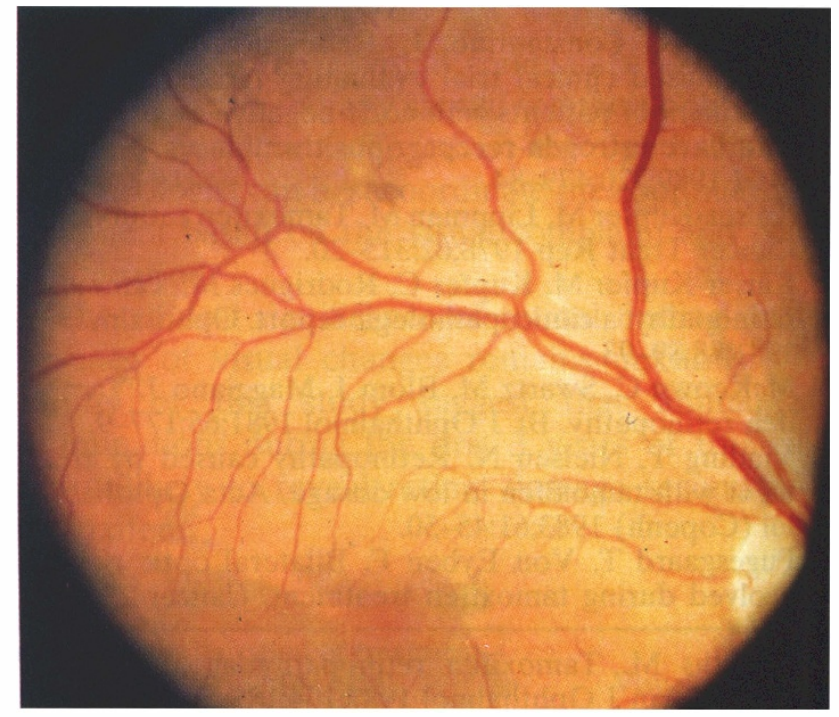

Fig. 1. Well-demarcated pigmented ovoid CHRPE lesion. 


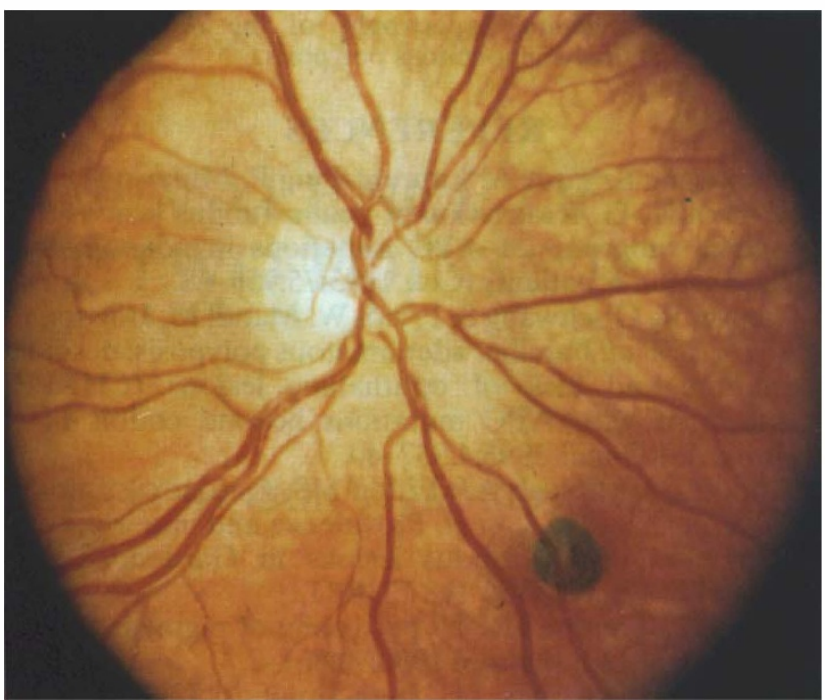

Fig. 2. A larger CHRPE lesion containing a depigmented area.

\section{METHOD}

Twelve patients from 12 different families in the Wessex region with FAP were analysed for any genotype-phenotype correlations. Each patient's mutation site was identified using a polymerase chain reaction (PCR)-based heteroduplex analysis method. Genomic DNA was amplified using the relevant primers. Heteroduplices were formed by heating the PCR product followed by cooling. The PCR products were separated by gel electrophoresis as described in Bunyan et al. ${ }^{5}$ The heteroduplex bands were then visualised by staining. Abnormal heteroduplex bands were subsequently analysed by direct sequencing, carried out using a Sequenase Version 2.0 T7 DNA Polymerase kit. Sequencing products were separated on gel and visualised by autoradiography. Data concerning polyp number and age of onset were found in the patient records.

All patients received a detailed fundus examination using a 90 dioptre lens and indirect ophthalmoscopy. CHRPE lesions were classified into two categories according to size, being called 'large' if their diameter was more than half the optic disc or otherwise 'small'. Most small lesions are punctiform and found mainly in the periphery. Large lesions are usually found in the posterior pole. Typically patients show a combination of large and small lesions. A parameter called the CHRPE coefficient was defined for each patient as the sum of the large lesions times three plus the number of small lesions. A CHRPE coefficient greater than 3 has been shown to be a strong indicator of a mutant APC gene inheritance. ${ }^{1}$

\section{RESULTS}

Group 1 individuals with mutations prior to exon 9 in the APC gene all had a CHRPE coefficient of less than 3, and were classified as CHRPE-negative. They
Table I. The APC gene mutations, CHRPE status, age when polyps were first seen and the number of polyps for each affected individual

\begin{tabular}{llcl}
\hline $\begin{array}{l}\text { Mutation } \\
\text { site }\end{array}$ & $\begin{array}{l}\text { CHRPE } \\
\text { status }\end{array}$ & $\begin{array}{l}\text { Age polyps first } \\
\text { seen (years) }\end{array}$ & $\begin{array}{l}\text { No. of } \\
\text { polyps }\end{array}$ \\
\hline Exon 4 & Negative & $31^{\mathrm{a}}$ & $100 \mathrm{~s}$ \\
Exon 7 & Negative & $29^{\mathrm{a}}$ & $100 \mathrm{~s}$ \\
Exon 9 & Negative & $43^{\mathrm{a}}$ & $80+$ \\
Exon 15A & Positive & $42^{\mathrm{a}}$ & $1000+$ \\
Exon 15A & Positive & $15^{\mathrm{a}}$ & $100+$ \\
Exon 15B & Positive & $28^{\mathrm{a}}$ & $1000+$ \\
Exon 15C & Positive & $53^{\mathrm{a}}$ & $100 \mathrm{~s}$ \\
Exon 15E & Positive & $37^{\mathrm{a}}$ & $100 \mathrm{~s}$ \\
Exon 15E & Positive & 25 & $250+$ \\
Exon 15F & Positive & $26^{\mathrm{a}}$ & $100+$ \\
Exon 15F & Positive & 28 & $1000+$ \\
Exon 15G & Positive & $15^{\mathrm{a}}$ & $1000+$ \\
\hline
\end{tabular}

${ }^{a}$ Polyps discovered in patient's colon during the first bowel screen.

also had fewer than 1000 colonic polyps. Group 2 individuals with mutations after exon 9 all had a CHRPE coefficient greater than 3 and were classified as CHRPE-positive. These patients had hundreds or thousands of polyps and generally presented earlier, usually in their teens or early twenties (Table I).

\section{DISCUSSION}

A more distal mutation site (beyond exon 9) generally leads to an earlier age of onset and a larger number of colonic polyps. In contrast a mutation earlier in the gene results in a milder form of FAP. Given that CHRPE lesions are seen when the mutation site is beyond exon 9 (with the exception of patients with mutations between codons 1445 and 1578) a patient with CHRPE stigma would thus be more likely to have a severe form of the disease..$^{5}$ It has been found that patients with severe desmoid disease lack CHRPE. ${ }^{2}$ Thus there seems to be a negative correlation between CHRPE and desmoid tumours.

As yet it is not possible to explain the variable expression of CHRPE as a function of the site of the APC mutation. A variation of functional domains has been described in the APC protein, one of which is the catenin binding domain, approximately located between codons 800 and 1200 , which is thought to be important for cell-cell adhesion. It is possible that mutations disrupting this region have consequences for retinal development, but as the site of mutations associated with CHRPE extends beyond the catenin binding domain in both directions, some mutant proteins would include this region and some would not. An alternative hypothesis is that the stability of mutant proteins may vary according to mutation site and may be tissue specific. There is good evidence that short and very long mutant proteins are indeed unstable, but variations in the stability of different truncated proteins within the CHRPE associated region have not been studied. ${ }^{6}$ 
As the mutation screening of the APC gene is expensive and time consuming (the APC gene has 8535 base pairs of coding sequence) the CHRPE status of an individual provides important information, which should allow a more rapid genetic confirmation of suspected FAP in future patients. The CHRPE status provides a guide to the likely position of the causative mutation and thereby an indication of the potential severity of disease.

In families with known CHRPE stigma an ophthalmological examination is a useful tool in determining the presence of the mutant APC gene in 'at risk' individuals. ${ }^{7}$ In these families, members with CHRPE need regular gastrointestinal investigations. Family members whose fundi have been examined and found to be devoid of CHRPE have a reduced risk of carrying the defective gene and therefore of developing polyps. Considerable reassurance can be gained from this; however, the only test which is $100 \%$ certain to exclude an individual from carrying the gene is mutation analysis. Such examinations should be carried out by an ophthalmologist who has experience in detecting CHRPE so as to get a reliable opinion for counselling purposes. If this is done, the CHRPE status in these families will be both an important and a useful tool in follow-up considerations.
Key words: Congenital hypertrophy of the retinal pigment epithelium, Familial adenomatous polyposis.

\section{REFERENCES}

1. Olschwang S, Tiret A, Laurent-Puig P, Muleris M, Parc $\mathrm{R}$, Thomas G. Restriction of ocular fundus lesions to a specific subgroup of APC mutations in adenomatous polyposis coli patients. Cell 1993;75:959-68.

2. Caspari R, Olschwang S, Friedl W, Mandl M, Boisson C, Boker T, et al. Familial adenomatous polyposis: desmoid tumours and lack of ophthalmic lesions (CHRPE) associated with APC mutations beyond codon 1444. Hum Mol Genet 1995;4:337-40.

3. Traboulsi EI, Krush AJ, Eldon MS, Gardner J, Booker SV, Offerhaus GJA, et al. Prevalence and importance of pigmented ocular fundus lesions in Gardener's syndrome. N Engl J Med 1987;316:11.

4. Blair NP, Trempe LT. Hypertrophy of pigment epithelium. Am J Ophthalmol 1980;90:661-7.

5. Bunyan DJ, Eccles D, Shea-Simonds J, Reck AC. Genotype-phenotype correlations of novel causative APC gene mutations in patients with familial adenomatous polyposis. J Med Genet 1995;32:924-31.

6. Eccles DM, Van der Luijt R, Breukel C, Bullman H, et al. Hereditary desmoid disease due to frameshift mutation at codon 1924 of the APC gene. Am J Hum Genet 1996;59:1193-201.

7. Burn J, Chapman P, Delhart J, et al. The UK Northern Region genetic register for familial adenomatous polyposis coli: use of age of onset, congenital hypertrophy of the retinal pigment epithelium, and DNA markers in risk calculations. J Med Genet 1991;28:289-96. 